\title{
O DIREITO DE EXISTIR PARA A SOCIEDADE: CIDADANIA E SEXUALIDADE NA LUTA POR DIREITOS DA COMUNIDADE LGBT NO BRASIL
}

Jacson Gross ${ }^{1}$

Daniela Mesquita Leutchuk de Cademartori ${ }^{2}$

Resumo: Este artigo tem como objetivo demonstrar a luta por uma cidadania sexual, através dos direitos de lésbicas, gays, bissexuais e transgêneros (LGBT). Parte-se dos estudos sobre cidadania e dos estudos sobre a construção social da sexualidade para buscar elementos para uma cidadania sexual em construção. A forma que a sexualidade é construída e que a cidadania é alcançada são os pontos em que o artigo transpassa os dois temas. As dificuldades encontradas na construção da identidade sexual, de aceitação do grupo LGBT na sociedade levam à reivindicação dos direitos de cidadania. Por fim, trata-se aqui dos direitos LGBT e da sua recepção e garantia pelo Direito Brasileiro.
Palavras-chave: Cidadania. Cidadania Sexual. Direitos LGBT. Sexualidade.

Abstract: This article aims to demonstrate the struggle for sexual citizenship through the lesbian, gay, bisexual and transgender (LGBT) rights. It starts with the studies on citizenship and studies on the social construction of sexuality to seek elements for a sexual citizenship under construction. The way that sexuality is constructed and that citizenship is achieved are the points at which the article passes over the two issues. The difficulties encountered in the construction of sexual identity, of acceptance of LGBT group in society lead to the claim of citizenship rights. Finally, this is about LGBT rights and its

\footnotetext{
${ }^{1}$ Graduado em Direito pela Universidade LaSalle (Unilasalle), mestre em Direito - área de concentração Direito e Sociedade - pela Universidade Lasalle (Unilasalle), e especialista em ensino de sociologia pela Universidade Federal de Santa Maria (UFSM). Atualmente é professor da graduação em Direito da Universidade LaSalle - (Unilasalle). Jacson.gross@ gmail.com

${ }^{2}$ Graduada em História e Direito pela Universidade Federal de Santa Maria (UFSM), mestra e doutora pela Universidade Federal de Santa Catarina (UFSC) e pósdoutorado pela Universidade Federal de Santa Catarina (UFSC). Atualmente é professora da graduação e pós-graduação em Direito da Universidade LaSalle - (Unilasalle).daniela.cademartori@unilasalle.edu.br
} 
receipt and warranty by the Brazilian law.

Keywords: Citizenship. Sexual Citizenship. LGBT Rights. Sexuality.

\section{Introdução}

Partindo-se da ideia da necessidade de aceitação da diversidade em sociedades complexas como as atuais, busca-se analisar o processo de construção da cidadania das minorias sexuais. Os integrantes destes grupos encontram-se na atualidade em situação de vulnerabilidade, na medida em que ao romper com o modelo heteronormativo de orientação sexual e identidade de gênero, sofrem preconceito, discriminação e intolerância, materializada na homofobia, transfobia, lesbofobia, etc. Este artigo debruça-se sobre os conceitos de cidadania e direitos, a fim de trazer ao centro da discussão tais entendimentos, permeando o conceito de construção social da sexualidade, onde os estudiosos, dentre eles Foucault, Weeks e Bozon, demonstram que ela não é algo que pertence somente à natureza devendo ser considerado o papel da cultura. Por fim, trata-se aqui dos direitos LGBT e da sua recepção e garantia pelo

Direito Brasileiro.

\section{Cidadania E Direitos}

A expressão cidadania induz a ideia de cidade. A expressão vem do latim e refere-se ao indivíduo que habita a cidade (civitas). (GORCZEVSKI; BELLOSO, 2011, p. 21). Já para Pinsky e Pinsky (2008, p. 9) o conceito de cidadania não é um conceito "fechado", mas um conceito histórico, o que significa que seu sentido varia no tempo e no espaço. É essa construção histórica, que faz com que na atualidade, a cidadania se vincule a ideia do direito a ter direitos - difundida por Hannah Arendt - deixando evidente o seu caráter técnico-jurídico.

Desse modo, o processo histórico de construção e ampliação da cidadania deixa evidente o seu caráter de construção e de luta por direitos, o que resulta em sua atual configuração. Contemporaneamente, se por um lado, ela é um conjunto de direitos civis, políticos e sociais, por outro, constitui-se como um sentimento comunitário de participação e, portanto, significa a exclusão dos integrantes que não comungam com esses sentimentos. Se todo cidadão necessariamente é membro 
de uma comunidade específica - seja qual for a sua organização - tal pertencimento é fonte de obrigações, ao mesmo tempo em que é também lócus de reivindicação de direitos. No cerne do conceito de cidadania subjaz seu caráter público e impessoal, de espaço e meio no qual conflitam aspirações e desejos dos grupos sociais, transformados em ações coletivas, que integram a comunidade, tendo como objeto a construção de projetos futuros. (CADEMARTORI; CADEMARTORI, 2007, p. 92).

Existe uma tensão entre a heterogeneidade que caracteriza a maior parte das sociedades complexas e o princípio da sua organização política. Este último, para fins de direitos e deveres, considera seus membros como parceiros iguais e desconsidera diferenciações divisões internas socioeconômicas, tais como as classes e de ordem regional, biológica e identitária, tais como grupos étnicos, linguísticos, religiosos, ou de gênero.

Quando, no século XVIII e na Europa Ocidental, ressurge a ideia de cidadania, as identidades coletivas não foram examinadas por pensadores e políticos. Primeiro porque, comparativamente estas sociedades apresentavam-se como relativamente homogêneas. Segundo, a heterogeneidade existente não chegou a constituir-se num problema como uma força tal capaz de incluí-lo nas agendas de reivindicações das lutas sociais.

As guerras religiosas tinham
terminado há muito, revoltas
regionais haviam sido reprimidas,
o Iluminismo enfatizava e
valorizava o que os seres humanos
tinham em comum, e o despertar
das nações estava ainda no futuro.
O cidadão então 'inventado' tinha
um discurso abrangente contra os
monarcas absolutistas, as
aristocracias com seus privilégios
inúteis, os sacerdotes
obscurantistas; mas tinha pouco a
dizer sobre como lidar com
diferenças de cor da pele, língua,
fé. (DEMANT, 2008, p. 343-344).

A situação modifica-se no século XIX, quando a expansão do conceito de "cidadão" leva a reivindicação da democracia como método capaz de possibilitar e legitimar a coexistência das diferenças. A solução encontrada visava unir as massas humanas, sob o impacto das revoluções política, industrial e demográfica, possibilitando a convivência das diferenças que emergiram. Naquele momento, acreditou-se que a aplicação de princípios gerais eliminaria os problemas oriundos das desigualdades particulares fazendo com que a cidadania 
emergente passasse a negar as diferenças entre os grupos. O método acabou por deparar-se com a uma realidade de ignorância, preconceitos, discriminações e perseguições ao que era considerado como diferente do padrão oficial.

$\mathrm{Na}$ década de cinquenta do século XX, Marshall (1967, p. 71-72) elaborou a mais clássica formulação do conceito moderno de cidadania. Segundo o autor, cada dimensão de cidadania está ligada a um tipo de direito: cidadania civil a direitos civis (direitos necessários à liberdade individual), cidadania política a direitos políticos (direitos de participação no exercício do poder político) e cidadania social a direitos sociais (direitos que incluem segurança e bem estar econômico, o direito de compartilhar da riqueza socialmente produzida e o de viver uma vida civilizada segundo padrões sociais condizentes).

\footnotetext{
${ }^{3}$ Bobbio (1992, p. 2) recorda que os direitos humanos são direitos históricos, porém discorda de que eles tenham surgido com a própria história do homem: "1. os direitos naturais são direitos históricos; 2. nascem no início da era moderna, juntamente com a concepção individualista da sociedade; 3. tornam-se uns dos principais indicadores do progresso histórico". Giuseppe Tosi (2005, p. 1) explicita a questão, lembrando que do ponto de vista histórico, “[...] estão aqui sendo confundidas duas realidades bem
}

A cidadania está extremamente ligada a noção de direitos humanos, e é na luta e na implementação desses direitos que o ser humano se faz cidadão. Sejam os diplomas legais internacionais (Carta das Nações Unidas de 1945, a Declaração Universal dos Direitos Humanos de 1948, Tratados Internacionais), diplomas constitucionais nacionais de cada Estado ou leis infraconstitucionais, são frutos de um processo histórico, de lutas, de conquistas, de retrocessos e avanços na busca de uma cidadania plena individual e coletiva.

Os conceitos de cidadania e de direitos humanos ${ }^{3}$ vão se tornando ao longo do tempo indissociáveis. Todavia, serão as modificações dos direitos fundamentais do homem no decorrer do tempo que irão dificultar a definição de um conceito preciso e sintético. Observa José Afonso da Silva (2000, p. 179), que

diferentes: a existência do direito e a existência dos direitos humanos. O direito (díkaion em grego, jus em latim) existe, pelo menos, desde que a humanidade começou a ter um Estado, isto é, desde o momento em que se constituem as primeiras civilizações; mas os direitos humanos são tipicamente modernos e ocidentais, isto é, nascem num determinado período histórico e numa determinada civilização: na Europa a partir do século XVI/XVII." 
[...] aumenta essa dificuldade a circunstancia de se empregarem várias expressões para designá-los, tais como: direitos naturais, direitos humanos, direitos do homem, direitos individuais, direitos públicos subjetivos, liberdades fundamentais, liberdades públicas, e direitos fundamentais do homem.

Os doutrinadores também divergem quanto às gerações de direitos. Adotar-se-á a divisão histórica clássica, como se encontra em Norberto Bobbio, e as atualizações e nomenclaturas desenvolvidas pelos doutrinadores contemporâneos. Bobbio (1992) dividiu os direitos fundamentais em gerações de direito, nas quais os direitos de primeira geração são os direitos individuais (pressupõem a igualdade formal perante a lei e consideram o sujeito abstratamente), os direitos de segunda geração são os direitos coletivos - (os direitos sociais, segundo os quais o sujeito de direito é visto no contexto social, ou seja, analisado em uma situação concreta), os direitos de terceira geração são os direitos dos povos ou direitos de solidariedade - (os direitos transindividuais, também conhecidos como direitos difusos ou coletivos, compreendendo os direitos do consumidor e relacionados às questões ecológicas e de meio ambiente) e os direitos de quarta geração são os direitos de manipulação genética - (os direitos relacionados à biotecnologia, bioengenharia, questões relacionadas à vida e morte). Ressaltamos que Bobbio (1992, p. 9), à época (primeira edição em língua portuguesa em 1992), delimita as gerações e descreve até a terceira geração de direitos, mas sinaliza que "já se apresentam novas exigências que só poderiam chamar-se direitos de quarta geração" referindo-se aos direitos vinculados à engenharia genética.

A primeira dimensão de direitos fundamentais é entendida como a dimensão que compreende os direitos a vida, a propriedade, a liberdade de locomoção, de participação política, são direitos que representam a vitória, ao menos parcial, do Estado Liberal sobre o Estado absolutista (MOTTA FILHO, 2007, p. 149). Lafer (1988, p. 126) ainda ressalta que essa dimensão é caraterizada pela individualidade e autonomia do ser frente ao Estado.

Em consonância a isso descreve Sarlet (2003, p. 52), "a nota distintiva destes direitos é a sua dimensão positiva, uma vez que se cuida não mais de evitar a intervenção do Estado na esfera da liberdade individual, mas, sim, de 
propiciar um 'direito de participar do bem-estar social"”.

Trata-se de um direito a liberdade do indivíduo frente ao Estado e frente ao outro indivíduo, é em suma, a observação da liberdade e o não agir do Estado em face desta.

A segunda dimensão de direitos fundamentais está ligada ao ideal de igualdade, de direitos sociais, econômicos e culturais, e ao Estado cabe instrumentalizar para que tais direitos se realizem. Assim, segundo Bonavides (1992, p. 518) são os direitos sociais, culturais, e econômicos, bem como os direitos coletivos ou de coletividades, introduzidos no constitucionalismo das distintas formas de Estado social [...]. Ainda, Sarlet (2003, p. 53) cita estes direitos como sendo "liberdades sociais, do que dão conta os exemplos de liberdade de sindicalização, do direito de greve, bem como dos direitos fundamentais dos trabalhadores [...]".

Nessa dimensão de direitos, ressalta-se que são prestações positivas proporcionadas pelo Estado direta ou indiretamente (SILVA, 2000, p, 289). Fazendo com que essas prestações positivas proporcionadas pelo Estado sejam responsáveis por uma amenização ou equalização da desigualdade combatida.

Nessa ótica afirma Bobbio (1992, p. 60) que,

\begin{abstract}
A história tem apenas o sentido que nós, em cada ocasião concreta, de acordo com a oportunidade, com nossos desejos e nossas esperanças, atribuímos a ela. E, portanto, não tem um único sentido. Refletindo sobre o tema dos direitos do homem, pareceume poder dizer que ele indica um sinal do progresso moral da humanidade.
\end{abstract}

Assim posta a questão, é possível perceber que o livre exercício da sexualidade está contemplado em pelo menos duas gerações de direitos fundamentais, na primeira geração, a qual abarca os direitos de liberdades individuais, direitos de característica negativa, contra intromissões abusivas. Como também, na segunda geração de direitos, de característica positiva, que devem promover a liberdade e a igualdade.

\section{A CONSTRUÇÃO SOCIAL DA SEXUALIDADE}

O conceito de sexualidade envolve diversas dimensões sejam elas pessoais, experiências sexuais pessoais, experiências religiosas, familiares ou políticas e econômicas. A sexualidade, segundo Weeks (2000, p. 38) "tem tanto a ver com as nossas crenças, ideologias e 
imaginação quanto com o nosso corpo

físico". Pode-se dizer que a sexualidade é multidimensional, permeando contextos sociais, históricos e culturais.

Vance (1995, p. 20) nos mostra que muitas vezes o termo sexualidade é simplificado de tal forma a esconder suas diversas dimensões e conexões.

O termo 'sexualidade' abrange uma variedade de tópicos. Seu significado é frequentemente dado como natural, ficando implícito como uma compreensão partilhada entre o leitor e o autor [...]. Considera-se que a sexualidade, os arranjos de gênero, a masculinidade e a feminilidade sejam conectados, até intercambiáveis. $\mathrm{O}$ gênero e a sexualidade estão inextrincavelmente unidos. Entretanto, esse pressuposto jamais explicitaria suas conexões culturais e históricas específicas; ao contrário, obscurece-as.

\section{A sexualidade humana é fruto}

de uma construção social, e assim sendo, não é fruto da natureza, mas da sociedade. E, como construção social

\footnotetext{
4 "Como cultivo, a cultura era concebida como uma ação que conduz a plena realização das potencialidades de alguma coisa ou de alguém; era fazer brotar, frutificar, florescer e cobrir de benefícios. No correr da Historia do Ocidente, esse sentido foi-se perdendo até que, no século XVIII, com a Filosofia da Ilustração, a palavra cultura ressurge, mas como sinônimo de outro conceito, torna-se sinônimo de civilização. Sabemos que civilização deriva-se de ideia de vida civil, portanto, de vida política e de regime político. Com o Iluminismo, a cultura e o padrão ou o critério que mede o grau de civilização de
}

não pode ser apreendida isoladamente, sendo produto do momento histórico, da cultura $^{4}$ e da sociedade na qual é inserido o indivíduo. Pode-se dizer que a sexualidade é um fenômeno social e cultural. $\mathrm{O}$ conceito de sexualidade conforme Weeks (2000, p. 40), descreve essa construção:

[...] a sexualidade é, na verdade, uma 'construção social', uma invenção histórica, a qual, naturalmente, tem base nas possibilidades do corpo: o sentido e o peso que lhe atribuímos são, entretanto, modelados em situações sociais concretas. Isso tem profundas implicações para nossa compreensão do corpo, do sexo e da sexualidade.

Ainda tratando da construção social da sexualidade Michel Bozon (2004, p. 14) explica que a sexualidade humana não é um dado da natureza, vinculando uma atividade corporal a uma atividade mental, consideradas ambas através da cultura.

Construída socialmente pelo contexto cultural em que está inscrita, essa sexualidade extrai

uma sociedade. Assim, a cultura passa a ser encarada como um conjunto de práticas (artes, ciências, técnicas, filosofia, os ofícios) que permite avaliar e hierarquizar o valor dos regimes políticos, segundo um critério de evolução. No conceito de cultura introduz-se a ideia de tempo, mas de um tempo muito preciso, isto é, contínuo, linear e evolutivo, de tal modo que, pouco a pouco, cultura torna-se sinônimo de progresso. Avalia-se o progresso de uma civilização pela sua cultura e avalia-se a cultura pelo progresso que traz a uma civilização”. (CHAUÍ, 2008, p. $55)$. 
sua importância política daquilo que contribui, em retorno, para estruturar as relações culturais das quais depende, na medida em que 'incorpora', e representa. [...] A sexualidade é uma esfera específica, mas não autônoma do comportamento humano, que compreende atos, relacionamentos, e significados [...]. A sexualidade não se explica pela própria sexualidade, nem pela biologia. A sociologia da sexualidade é um trabalho infinito de contextualização social e cultural que visa estabelecer relações múltiplas, e por vezes, desconhecidas, dos fenômenos sexuais com os processos sociais, o que se pode chamar de construção social da sexualidade.

\section{Para o filósofo francês Foucault}

(1999), a sexualidade tomou a função de controle dos indivíduos e das populações, de separação entre normalidade e anormalidade, de aceita e de não aceita socialmente. Ela tornou-se instrumento de separação entre práticas sexuais consideradas bem educadas e as demais. O sexo bem educado ou normatizado era na década de 1980 nas pesquisas de Foucault, e ainda é em parte, hoje, aquele com práticas heterossexuais, monogâmicas, reprodutivas, e chancelado pelo matrimônio. As demais práticas sexuais

\footnotetext{
5 Onanista é o indivíduo que interrompe o ato sexual antes da ejaculação e o que pratica o ato da masturbação. (POLITO, 2004).

6 McFarlane (1990) denominou de casamento malthusiano o modelo de união conjugal que tem
}

eram relegadas à marginalização. São casos de práticas marginalizadas, os do homossexual, do onanista ${ }^{5}$ e do casal malthusiano ${ }^{6}$. Tratando da sexualidade, Foucault (1999, p. 100) acrescenta:

A sexualidade é o nome que se pode dar a um dispositivo histórico: não à realidade subterrânea que se aprende com dificuldade, mas à grande rede de superfície em que a estimulação dos corpos, a intensificação dos prazeres, a incitação ao discurso, a formação dos conhecimentos, o reforço dos controles e das resistências, encadeiam-se uns aos outros, segundo algumas grandes estratégias de saber e poder.

O termo "dispositivo" na teoria foucaltiana é entendido como uma rede heterogênea que pode se estabelecer entre organizações arquitetônicas, instituições, discursos, decisões regulamentares, leis, medidas administrativas, enunciados científicos e mesmo, proposições filosóficas. Em resumo o dito e o não dito. (REVEL, 2005, p.40). E, por essa razão, Foucault usa o termo dispositivo da sexualidade por entender que a sexualidade é uma construção em rede.

como premissas básicas o afeto, a amizade e o companheirismo entre os cônjuges e a procriação não é o objetivo principal do casamento. 
Tais redes de relações pressupõem relações de poder, capazes de mudar, desenhar e redesenhar dada época, dado objeto perseguido, e a alternância dos polos do poder ou até mesmo sua simultaneidade (REVEL, 2005, p. 67). Através delas são ditados os comportamentos a serem seguidos, as sexualidades concebidas como corretas, e por conseguinte, aceitas. Nasce a heteronormatividade ditada socialmente como modelo a ser seguido.

Diante do exposto, é possível perceber que a sexualidade é um produto cultural, que os padrões são produzidos e reproduzidos e, mutáveis. Um exemplo atual dessa mutabilidade é o caso do cartunista brasileiro Laerte Coutinho, que após 40 anos de carreira e 61 de vida, três casamentos heterossexuais e filhos, pôs em xeque - não sem sofrimento, segundo ele -, as definições de gênero e os limites da liberdade individual. Laerte passou a vestir-se e comportar-se como mulher e hoje, identifica-se como bissexual $^{7}$. O modo como o cartunista brasileiro tornou pública a mudança, não são comuns, eis que a heteronormatividade na qual estamos

\footnotetext{
${ }^{7}$ Laerte Coutinho é um cartunista e chargista brasileiro, que colocou em xeque definições de
}

imersos faz com que sexualidades divergentes do padrão heterossexual tendam a ser invisibilizadas e culpabilizadas.

Nesse ponto, faz-se necessário explicitar o significado do vocábulo heteronormatividade. Formado pela conjunção de duas palavras "hetero" e "norma", sendo que o vocábulo "hetero" significando diferente, de outro e antônimo de "homo" ou igual. Ao passo que, o vocábulo "norma", tem por significado, preceito, regra, valor, modelo (PETRY; MEYER, 2011, p. 196; POLITO, 2004). Nota-se o quão carregado de significado é o termo heteronormatividade. A partir desses termos pode-se definir heteronormatividade como modelo de relação com pessoa de sexo diferente do seu, a ser seguido como regra, ditado socialmente como modelo de valor. A heteronormatividade é entendida por Foster (2001, p. 19) como

a reprodução de práticas e códigos
heterossexuais, sustentada pelo
casamento monogâmico, amor
romântico, fidelidade conjugal,
constituição de família (esquema
pai-mãe-filho (a) (s)). Na esteira
das implicações da aludida
palavra, tem-se o heterossexismo
gênero e os limites da liberdade individual. (LAERTE, 2012). 
compulsório, sendo que, por esse último termo, entende-se o imperativo inquestionado e inquestionável por parte de todos os membros da sociedade com o intuito de reforçar ou dar legitimidade às práticas heterossexuais.

As homossexualidades ${ }^{8}$

estiveram presentes no catálogo de Classificação Internacional de Doenças (CID) no rol de doenças mentais até o final do século XX. Em 1990 elas foram retiradas desta classificação a pedido da Organização Mundial da Saúde (OMS). O termo homossexualidade carrega em si, uma carga de significação, como Fry e Macrae (1991, p. 7) descrevem:

O problema é que a homossexualidade é uma infinita variação sobre um mesmo tema: o das relações sexuais e afetivas entre pessoas do mesmo sexo. Assim, ela é uma coisa na Grécia Antiga, outra coisa na Europa do fim do século XIX, outra coisa ainda entre os índios Guaiqui do Paraguai. Com esse mesmo raciocínio, a homossexualidade pode ser uma coisa para um camponês do Mato Grosso, outra coisa para um candidato a governador do estado de São Paulo [...] tantas coisas quanto os diversos segmentos sociais da sociedade brasileira contemporânea.

Fry e Macrae (1991, p. 8-9) apontam também o quanto essas

\footnotetext{
${ }^{8}$ Adotar-se-á o termo homossexualidades(s) por se entender que a presença do sufixo "ismo" na palavra homossexualismo ainda carregue
}

identificações pessoais variam de um lugar para outro, de um segmento social para outro. Trazendo alguns exemplos, mostram que em determinado lugar, um homem que mantem relações sexuais com outro homem, pode não se identificar como homossexual, ou um jovem rapaz, que mantém relação sexual com um senhor mais velho, por uns trocados, talvez também não se identifique como tal. Essa identificação ou não, seja ela uma identificação pessoal ou social, impossibilitam que o termo homossexualidade possa ser condensado em um conceito sintético.

Em suma, a identidade de gênero se relaciona com as identificações histórico-sociais dos sujeitos, que se reconhecem como femininos ou masculinos, e a orientação sexual é a forma como os indivíduos sentem e experimentam seus desejos. (LOURO, 2000). Segundo Borrillo (2009), as divisões de gênero e de desejo são identificações relacionadas com a reprodução da norma social, e não com a reprodução biológica da espécie. Portanto, representariam relações de

caracteres de associação à doença / distúrbio mental. 
poder como já citado por Foucault anteriormente.

\section{Considerações Sobre As Violações Aos}

\section{Direitos LGBT No Brasil}

Em 2013, informa pesquisa do Grupo Gay da Bahia (GGB) um homossexual era assassinado no Brasil a cada 28 horas $^{9}$, sendo que a metade dos assassinatos homofóbicos do mundo, são cometidos somente no Brasil.

Agressões;

torturas;

discriminação em órgãos e por autoridades governamentais; discriminação econômica, contra a livre movimentação, privacidade e trabalho; discriminação familiar, escolar, científica e religiosa; difamação e discriminação na mídia; insultos e preconceito anti-homossexual; lesbofobia: violência antilésbica; travestifobia. Essas são algumas formas comuns - e que muitas vezes passam despercebidas - de violência sofridas pela comunidade $\mathrm{LGBT}^{10}$. A homofobia tem múltiplas formas de expressão: desde piadas até representações

\footnotetext{
${ }^{9}$ Pesquisa disponível no sitio do Grupo Gay da Bahia. Disponível em: <http://www.ggb.org.br/direitos.html.>.

10 LGBT - Sigla que reúne lésbicas, gays, bissexuais, travestis, transexuais e transgêneros, sujeitos políticos do movimento social que os representa, definida em convenção dos grupos e
}

estereotipadas que personificam determinadas características do ente que sofre a agressão no termo usado, lesbofobia, bifobia, transfobia. Pode-se dizer que a homofobia é a reação hostil às sexualidades desviantes da norma heterossexual.

$\mathrm{Na}$ atualidade, o parlamento brasileiro eleito no pleito de 2014 , tem sido considerado o mais conservador no período do pós-1964 ${ }^{11}$, podendo fazer com que as pautas LGBT corram o risco de ficarem esquecidas. No entanto, passos foram dados nesta seara: alguns Estados estabelecem proibições de discriminação por motivos de orientação sexual, tais como o Mato Grosso, Sergipe, Piauí, e o Distrito Federal (em sua Lei Orgânica), uma vez que na Constituição Federal não há menção expressa proibindo a discriminação por motivo de orientação sexual.

Até o ano de 2013, na Câmara dos Deputados Federal existiam 20 proposições em pauta, relacionadas à união ou ao casamento entre pessoas do

ONGs que compõem esse movimento na I Conferência Nacional GLBT, ocorrida em 2008, onde aprovaram o documento chamado "Carta de Brasília".

11 Segundo dados do DIAP - Departamento Intersindical de Assessoria Parlamentar. 
mesmo sexo, sendo nove favoráveis, oito contrárias e três neutras. Ainda, têm-se no âmbito penal os projetos de proposição da criminalização da homofobia, englobando orientação sexual e identidade de gênero. (OLIVEIRA, 2013, p. 97).

A Associação Brasileira de Lésbicas, Gays, Bissexuais, Travestis e Transexuais (ABGLT) lista em seu sítio ${ }^{12}, 78$ direitos negados a casais homossexuais, no entanto, acredita-se que existam mais de cem direitos correlatos negados às pessoas $\mathrm{LGBT}^{13}$ (Lésbicas, Gays, Bissexuais, Travestis, Transexuais, Transgêneros) no Brasil.

A legislação brasileira ainda é bastante omissa no que tange aos direitos LGBT. Os direitos de cidadania do grupo LGBT são, de fato, deixados de lado pelo legislador que se omite na hora da formulação de leis que defendam essas minorias, e isso ocorre - muitas vezes - por questões religiosas, morais, bem como pelo temor de alguns parlamentares de eventuais reflexos

12 Conforme sítio da ABGLT - Disponível em: <http://www.abglt.org.br/port/78direitosnegados .php>.

${ }^{13}$ LGBT é a sigla oficial usado no Brasil a partir de 2008. LGBTI é o termo usado por organismos eleitorais frente a grupos conservadores da sociedade.

Ressalta-se que dada a situação de violações à direitos humanos vivenciada pelos grupos LGBT, necessária se faz a positivação destes direitos de modo a acompanhar as mudanças sociais que interferem na construção da sexualidade. É importante ter a ciência de que, independente de qual sexualidade seja, a opção sexual não se reveste de caracteres de doença compreensão que apesar da desclassificação no CID, ainda subsiste na sociedade - tratando-se de uma escolha pessoal, desenhada pela história, pela cultura, em suma, pelo próprio meio em que o indivíduo está inserido.

\section{A Demanda Por Direitos}

O grupo LGBT brasileiro teve início com o que se pode chamar de Movimento Homossexual Brasileiro, alicerçado no grupo "Somos" - primeiro grupo reconhecido como tendo uma proposta de defesa de demandas homossexuais, fundado em 1978, em São Paulo (FACCHINI, 2005, p. 66). No

internacionais para designar o mesmo grupo, com a inclusão da letra "I" para destacar os indivíduos intersexuais. Adotaremos o termo oficial brasileiro que contempla todas as representações sexuais. 
final da década de 1990, surge o Grupo CORSA. Nesse segundo momento, o grupo "Somos" cresce tendo a adesão inclusive de mulheres, e novos grupos se formam: o "Eros" e o "Libertos". Já em 1979, é organizado no Rio de Janeiro $(\mathrm{RJ}), \quad \mathrm{o}$ primeiro encontro de homossexuais militante, e a partir daí, outros encontros aconteceram, outros grupos foram formados espalhando o movimento pelo país. (FACCHINI, 2005, p. 67)

$\mathrm{Na}$ primeira metade dos anos 1980 (FACCHINI, 2005, p. 73) com o surgimento da Síndrome da Imunodeficiência Adquirida (AIDS), tida inicialmente como "peste gay" ou “câncer gay”, houve redução dos grupos, bem como uma mudança de foco na atuação destes, que passaram a preocupar-se com a luta contra a epidemia. Essa reação é tida como uma das primeiras respostas da sociedade civil brasileira à epidemia de AIDS.

A partir de 1992, a quantidade de grupos nos encontros nacionais começa a crescer novamente (FACCHINI, 2005, p. 87 e 101), diversificando os formatos institucionais e propostas de atuação.
Essas instituições, Organizações Não Governamentais (ONGs), fundações, entre outras nomenclaturas, tem papel fundamental na sociedade brasileira, uma vez que representam o grupo LGBT frente ao Estado reivindicando direitos, que em sua maioria são alcançados apenas na esfera judicial.

\section{A constitucionalização dos direitos}

Rios, Souza e Sponchiado (2014, p. 164-174) lembram que na Constituição brasileira não há proibição expressa de discriminação por motivo de orientação sexual. No tocante às leis federais há quatro diplomas legislativos que tratam o tema da discriminação. $\mathrm{O}$ primeiro envolve a proibição de discriminação por motivo de “preferência sexual” (Lei nº 9.612/1998, $\operatorname{artigo} 4^{\circ}$, inciso IV): "não discriminação de raça, religião, sexo, preferências sexuais, convicções político-ideológicopartidárias e condição social nas relações comunitárias". (BRASIL, 1998). O segundo veda qualquer forma de discriminação em relação a pessoas portadoras de transtornos mentais, colocando a orientação sexual como critério proibido (Lei $\mathrm{n}^{\mathrm{o}}$ 10.216/2001, 
artigo $1^{\circ}$ ): "Os direitos e a proteção das pessoas acometidas de transtorno mental, de que trata esta Lei, são assegurados sem qualquer forma de discriminação quanto à raça, cor, sexo, orientação sexual, religião, opção política, nacionalidade, idade, família, recursos econômicos e ao grau de gravidade ou tempo de evolução de seu transtorno, ou qualquer outra". (BRASIL, 2001). O terceiro diploma garante direitos fundamentais a toda mulher, independente de orientação sexual (Lei Maria da Penha, artigo $2^{\circ}$ ): "Toda mulher, independentemente de classe, raça, etnia, orientação sexual, renda, cultura, nível educacional, idade e religião, goza dos direitos fundamentais inerentes à pessoa humana, sendo-lhe asseguradas as oportunidades e facilidades para viver sem violência, preservar sua saúde física e mental e seu aperfeiçoamento moral, intelectual e social”. (BRASIL, 2006b). E finalmente, proíbe-se anotações que incorporem informações não vinculadas à análise do risco de crédito (Lei no 12.414/2011, artigo $3^{\circ}$, inciso II), “informações sensíveis, assim consideradas aquelas pertinentes à origem social e étnica, à saúde, à informação genética, à orientação sexual e às convicções políticas, religiosas e filosóficas". (BRASIL, 2011a).

\section{Direitos no âmbito civil}

Uma das facetas da luta por direitos é a que envolve o direito de família: o direito de constituir e ter sua família reconhecida e protegida pela legislação nacional. Seara onde encontram-se as discussões acirradas sobre o direito à adoção por casais homossexuais entre outros direitos ainda não conquistados pelo grupo LGBT.

Em cinco de maio de 2011, o Supremo Tribunal Federal (STF) julgou a Ação Direta de Inconstitucionalidade (ADI) $\mathrm{n}^{\circ} 4.277$ e a Arguição de Descumprimento de Preceito Fundamental (ADPF) $\quad \mathrm{n}^{\mathrm{o}} \quad 132$, reconhecendo a União Estável entre casais do mesmo sexo. Excluiu, assim, qualquer significado do artigo 1.723 do Código Civil (CC) que impeça o reconhecimento da união das pessoas do mesmo sexo como entidade familiar. Reza o citado artigo: "É reconhecida como entidade familiar a união estável entre o homem e a mulher, configurada na convivência pública, contínua e duradoura e estabelecida com o objetivo 
de constituição de família”. Dessa maneira, conferiu interpretação a esse dispositivo à luz da Constituição Federal, em seu artigo $3^{\circ}$, inciso IV, que veda qualquer discriminação em virtude de sexo, raça ou cor. O relator da ação, Ministro Carlos Ayres Britto, em seu voto, resume: "A nossa Magna Carta não emprestou ao substantivo família nenhum significado ortodoxo". E acrescenta: "Não existe família de segunda classe ou família mais ou menos". (BRASIL, 2011c, p. 24 e 29).

Em matéria civil ainda existem outras proposituras na Câmara dos Deputados em relação a casamento ou união de pessoas do mesmo sexo.

\section{Direitos no âmbito penal}

Em matéria penal destacam-se os projetos de lei $\mathrm{n}^{\mathrm{o}} 2.773 / 2000$ de autoria do Deputado Alceste Almeida (PTB-RR) e 6.871/2006 de autoria da deputada Laura Carneiro (PFL ${ }^{14} / \mathrm{PTB}-$ RJ), os quais excluem do Código Penal Militar o crime de "pederastia", bem como diversos projetos de lei que criminalizam condutas homofóbicas, as quais, em última análise, são discriminações por motivo de orientação sexual, contrárias ao ordenamento jurídico (BRASIL, 2000, 2006a). E a proposição da criminalização da homofobia que tenta englobar a orientação sexual e identidade de gênero que desde 2001 tramita nas casas legislativas, inicialmente na Câmara dos Deputados, e agora no Senado sob o registro Projeto de Lei da Câmara (PLC) $122 / 2006$. Este projeto foi aprovado com substitutivos, e encontra-se atualmente apensado ao projeto de reforma do Código Penal, impossibilitando sua tramitação. No Senado Federal também encontra-se o Projeto de Lei do Senado (PLS) nº 457/2011 de autoria do Senador Pedro Taques (PDT-MT), o qual "aumenta a pena dos crimes contra a honra, previstos nos arts. $\mathrm{n}^{\circ} 138,139$ e 140 , caput e $\S 2^{\circ}$; altera a redação do $\S 3^{\circ}$ do art. 140, para incluir a orientação sexual e identidade de gênero como elementos para injúria qualificada" (OLIVEIRA, 2013, p. 102).

\section{Conclusões}

O Brasil, infelizmente, continua recordista mundial de desigualdade, seja

${ }^{14}$ O Partido da Frente Liberal (PFL) foi extinto em 2007. 
ela social, regional e de gênero. Concentramos uma das mais elevadas rendas do mundo e, ao mesmo tempo, temos um dos maiores índices de pobreza do planeta. Já chegamos a ocupar o $8^{\circ}$. lugar na economia mundial, mas fomos rebaixados para $15^{\circ}$. no ranking da Organização Mundial do Comércio. Um terço do Brasil é miserável. Outro terço, para sermos extremamente otimistas, não dispõe de dinheiro suficiente para atender às necessidades mais básicas de alimentação, vestuário, habitação, transporte e educação. As desigualdades regionais brasileiras são imensas. A taxa de analfabetismo do Nordeste, por exemplo, é, no mínimo, três vezes maior que no Sul. No campo rural, a situação é ainda mais dramática: a proporção de analfabetos dobra em relação à media nacional. Não menos terrível é a desigualdade racial. Para a população negra - mais da metade da população brasileira segundo censo de 2010 - as vantagens do progresso e os direitos de cidadania custam ainda mais a chegar.

A desigualdade tem por característica trazer consigo uma carga de injustiças, sejam elas, sociais, econômicas, raciais, regionais, culturais, entre outras, muitas delas históricas, tornando seu saneamento mais difícil e complexo. Nesse cenário cruel, a desigualdade de gênero constitui um fator a mais no mapa da desigualdade. As violações aos direitos LGBT, que estatisticamente vem aumentando, contrastam com as poucas políticas públicas e jurídicas voltadas ao grupo, fazendo com que sejam negados direitos de cidadania a essa minoria.

\section{Referências}

Bobbio, Norberto (1992), A era dos direitos. Tradução Carlos Nelson Coutinho. Rio de Janeiro: Campus. Tradução de: L'età dei diritti. [11. ed.].

Bonavides Paulo (2006), Curso de direito constitucional. São Paulo: Editora Malheiros. [19. ed.].

Bonavides Paulo (2010), "A quinta geração de direitos fundamentais", Revista Direitos Fundamentais \& Justiça, 3, 82-93.

Borrillo, Daniel (2009), "A homofobia”, in Diniz, Debora; Lionço, Tatiana (Orgs.). 
Homofobia \& Educação: um desafio ao silêncio. Brasília: Letras Livres, 15-46.

Bozon, Michel (2004), Sociologia da sexualidade. Tradução Maria de Lourdes Menezes. Rio de Janeiro: Ed. FGV. Tradução de: Sociologie de la sexualité.

Brasil (1916), Lei $\mathrm{n}^{\mathrm{o}} 3.071$, de $1^{\circ}$ de janeiro de 1916. Código Civil dos Estados Unidos do Brasil. Consultado a 02.09.2013, em http://www.planalto.gov.br/ccivil_03/lei s/13071.htm.

Brasil (1988), Constituição, Constituição da República Federativa do Brasil de 1988. Consultado a 02.09.2013, em http://www.planalto.gov.br/ccivil_03/co nstituicao/constituicao.htm.

Brasil (1990), Lei $\mathrm{n}^{\circ}$ 8.069, de 13 de julho de 1990. Dispõe sobre o Estatuto da Criança e do Adolescente e dá outras providências. Consultado a 02.09.2013, em

http://www.planalto.gov.br/ccivil_03/lei s/18069.htm.

Brasil (1998), Lei $\mathrm{n}^{\circ} 9.612$, de 19 de fevereiro de 1998. Institui o serviço de radiodifusão comunitária e dá outras providências. Consultado a 19;12.2013, em

http://www.planalto.gov.br/ccivil_03/lei s/19612.htm.

Brasil (2000), Câmara dos Deputados, Projeto de lei $n^{\circ} 2.773 / 2000$. Altera a redação do art. 235, do Código Penal Militar, excluindo do texto o crime de pederastia. Consultado a 30.07.2014, em http://www.camara.gov.br/proposicoes Web/fichadetramitacao?idProposicao=1 8609.

Brasil (2001), Lei no 10.216, de 6 de abril de 2001. Dispõe sobre a proteção e os direitos das pessoas portadoras de transtornos mentais e redireciona $\mathrm{o}$ modelo assistencial em saúde mental. Consultado a 19;12.2013, em http://www.planalto.gov.br/ccivil_03/lei s/leis_2001/110216.htm.

Brasil (2006a), Câmara dos Deputados, Projeto de lei $\mathrm{n}^{\circ} 6.871 / 2006 \mathrm{a}$. Altera a redação do art. 235 do Código Penal Militar, excluindo do nome jurídico o termo "pederastia" e do texto a expressão "homossexual ou não" e acrescentando parágrafo único, para excepcionar a 
incidência. Consultado a 30;07.2014, em http://www.camara.gov.br/proposicoes

Web/fichadetramitacao?idProposicao $=3$ 19817.

Brasil (2006b), Lei ${ }^{\circ} 11.340$, de 7 de agosto de 2006b. Cria mecanismos para coibir a violência doméstica e familiar contra a mulher, nos termos do $\S 80$ do art. 226 da Constituição Federal, da Convenção sobre a Eliminação de Todas as Formas de Discriminação contra as Mulheres e da Convenção Interamericana para Prevenir, Punir e Erradicar a Violência contra a Mulher; dispõe sobre a criação dos Juizados de Violência Doméstica e Familiar contra a Mulher; altera o Código de Processo Penal, o Código Penal e a Lei de Execução Penal; e dá outras providências. Consultado a 19.12.2013, em

http://www.planalto.gov.br/ccivil_03/_a to2004-2006/2006/lei/111340.htm.

Brasil (2011a), Lei $\mathrm{n}^{\circ}$ 12.414, de 9 de junho de 2011a. Disciplina a formação e consulta a bancos de dados com informações de adimplemento, de pessoas naturais ou de pessoas jurídicas, para formação de histórico de crédito. http://www.planalto.gov.br/ccivil_03/_ Ato2011-2014/2011/Lei/L12414.htm.

Brasil (2011b), Supremo Tribunal Federal. Ação direta de inconstitucionalidade $\quad \mathrm{n}^{\mathrm{o}} \quad 4.277 / \mathrm{DF}$. Relator: Ministro Ayres Brito. Brasília, 05 de maio de 2011b. Consultado a 02.09. 2013, em http://www.stf.jus.br/portal/geral/verPdf Paginado.asp? $\mathrm{id}=400547 \&$ tipo $=$ TP $\&$ de scricao $=\mathrm{ADI} \% 2 \mathrm{~F} 4277$.

Brasil (2011c), Supremo Tribunal Federal. Argüição de descumprimento de preceito fundamental $n^{0} 132 / R J$. Relator: Ministro Ayres Brito. Brasília, 05 de maio de 2011c. Consultado a 02.09.2013, em http://redir.stf.jus.br/paginadorpub/pagi nador.jsp?docTP=AC\&docID=628633.

Butler, Judith (2000), "Corpos que pesam: sobre os limites discursivos do sexo". in Louro, Guacira Lopes (Org.). O corpo educado: pedagogias da sexualidade. Belo Horizonte: Autêntica, 151-172. [2. ed.]. 
Cademartori, Daniela Mesquita Tradução Maria Thereza da Costa Leutchuk de; Cademartori, Sérgio Albuquerque, J. A. Guilhon Urquhart (2007), “Mutações da cidadania: da comunidade ao Estado liberal", Revista Sequência, PPGDUFSC, 55, 65-94.

Albuquerque. Rio de Janeiro: Edições Graal. Tradução de: Histoire de la sexualité I: la volonté de savoir. [13. ed.].

Chaui, Marilena (2008), "Cultura e Fry, Peter; Macrae, Edward (1991), O democracia", Crítica y emancipación: Revista Latinoamericana de Ciencias Sociales, 1(1), 53-76.

Demant, Peter (2008), "Direitos para os excluídos", in Pinsky, Jaime; Pinsky, Carla Bassanezi (Orgs.). História da cidadania. São Paulo: Contexto, 343383. [4. ed.].

Facchini, Regina (2005), Sopa de letrinhas?: movimento homossexual e produção de identidades coletivas nos anos 90. Rio de Janeiro: Garamond.

Foster. David W (2001), "Consideraciones sobre el estudio de la heteronormatividade en la literatura latino-americana”, Letras: Literatura e Autoritarismo, 22. que é homossexualidade? São Paulo: Brasiliense. [7. ed.].

Gorczevski, Clovis; Belloso, Nuria (2011), A necessária revisão do conceito de cidadania: movimentos sociais e novos protagonistas na esfera pública democrática. Santa Cruz do Sul: EDUNISC. Consultado a 27.11.2014, em:

http://www.unisc.br/portal/upload/com_ editora_livro/e_book.pdf.

Laerte (2012), "Cartunista, colocou em xeque definições de gênero e os limites da liberdade individual", Trip Transformadores. Consultado a 15.01.2015, em: http://revistatrip.uol.com.br/transformad ores/site/homenageados/index.php?cod $=92$.

Foucault, Michel (1999), História da Sexualidade. v. 1: A vontade de saber. 
Lafer, Celso (1988), A reconstrução dos direitos humanos: um diálogo com o pensamento de Hannah Arendt. São Paulo: Companhia das Letras. [1. ed.].

Louro, Guacira Lopes (2000), "Pedagogias da sexualidade", in Louro, Guacira Lopes (Org.). O corpo educado: pedagogias da sexualidade. Belo Horizonte: Autêntica, 7-34. [2. ed.].

Marshall, Thomas Humphrey (1967), Cidadania, classe social e status. Tradução Meton Porto Gadelha. Rio de Janeiro: Zahar. Tradução de: Sociology at the crossroads and other essays.

McFarlane, Alan (1990), História do casamento e do amor: Inglaterra, 13001840. Tradução Paulo Neves. São Paulo: Companhia das Letras. Tradução de: Marriage and love in England: Modes of reproduction, 1300-1840.

Motta Filho, Sylvio Clemente da; Barchet, Gustavo (2007), Curso de direito constitucional: atualizado até a Emenda Constitucional $n^{\circ} 53 / 2006$. Rio de Janeiro: Elsevier.
Oliveira, Rosa Maria Rodrigues de (2013), Direitos sexuais de LGBTTT no Brasil:

jurisprudência, propostas legislativas e normatização federal. Brasília:

Ministério da Justiça.

Petry, Analídia Rodolpho; Meyer, Dagmar Elisabeth Estermann (2011), "Transexualidade heteronormatividade: algumas questões para a pesquisa", Textos \& Contextos, 10(1), 193 - 198.

Pinsky, Jaime; Pinsky, Carla Bassanezi (Orgs.) (2008), História da cidadania. São Paulo: Contexto. [4. ed.].

Polito, Andre Guilherme (2004), Michaelis: moderno dicionário da língua portuguesa. São Paulo: Melhoramentos. [1. ed.].

Revel, Judith (2005), Michel Foucault: conceitos essenciais. Tradução Maria do Rosário Gregolin, Nilton Milanez, Carlo Piovesani. São Carlos: Claraluz. Tradução de: Le vocabulaire de Foucault. 
Rios, Roger Raupp (2001), A homossexualidade no direito. Porto Alegre: Livraria do Advogado.

Rios, Roger Raupp (2008), Direito da antidiscriminação: discriminação direta, indireta e ações afirmativas. Porto Alegre: Livraria do Advogado.

Rios, Roger Raupp; Souza, Luiz Gustavo Oliveira de; Sponchiado, Tobias (2014), "Notícias de homofobia e proteção jurídica antidiscriminatória", in Diniz, Debora; Oliveira, Rosana Medeiros de. (Orgs.). Notícias de homofobia no Brasil. Brasília: LetrasLivres, 159-190.

Sarlet, Ingo Wolfgang (2003), A eficácia dos direitos fundamentais. Porto Alegre: Livraria do Advogado.

Silva, José Afonso da (2000), Curso de direito constitucional positivo. São Paulo: Malheiros. [18. ed.].

Tosi, Giuseppe (2014) "História conceitual dos direitos humanos", in Tosi, Giuseppe, Direitos humanos: história, teoria e prática. João Pessoa: Editora Universitária (UFPB), 99-125. Consultado a 01.11.2014, em http://www.dhnet.org.br/dados/livros/ed h/br/pbunesco/i_01_anotacoes.html\#1.

Vance, Carole (1995), “A antropologia redescobre a sexualidade: um comentário teórico", Physis: Revista de Saúde Coletiva, 5(1), 7-31.

Weeks, Jeffrey (2000), "O corpo e a sexualidade". Tradução Tomaz Tadeu da Silva, in Louro, Guacira Lopes. (Org.). O corpo educado: pedagogias da sexualidade. Belo Horizonte: Autêntica, 35-82. Tradução de: The body and sexuality. [2. ed.]. 